Témoigner Témoigner. Entre histoire et mémoire

Getuigen Revue pluridisciplinaire de la Fondation Auschwitz

$126 \mid 2018$

Questions sur l'avenir du travail de mémoire

\title{
Riphagen, Jodenjager in Amsterdam (Pieter Kuijpers)
}

\section{Brecht Capiau}

\section{OpenEdition}

1 Journals

Édition électronique

URL : https://journals.openedition.org/temoigner/7075

DOI : 10.4000/temoigner.7075

ISSN : 2506-6390

\section{Éditeur :}

Éditions du Centre d'études et de documentation Mémoire d'Auschwitz, Éditions Kimé

\section{Édition imprimée}

Date de publication : 2 avril 2018

Pagination : 20-23

ISBN : 978-2-930953-06-9

ISSN : 2031-4183

\section{Référence électronique}

Brecht Capiau, «Riphagen, Jodenjager in Amsterdam (Pieter Kuijpers)», Témoigner. Entre histoire et mémoire [Online], 126 | 2018, Online op 20 janvier 2022, geraadpleegd op 04 février 2022. URL: http:// journals.openedition.org/temoigner/7075 ; DOI: https://doi.org/10.4000/temoigner.7075 


\section{RIPHAGEN JODENJAGER IN AMSTERDAM} (PIETER KUIJPERS)

FILM Twee piekfijn uitgedoste heren bellen aan bij een rijwoning in Amsterdam. De mannen stellen zich voor als Andries Riphagen en Joop Out, leden van het Divisenschutzkommando. Ze zijn op zoek naar Joden. Eenmaal binnen bij de familie De Wit speurt Riphagen naar potentiële schuilplekken terwijl Out het bejaarde koppel uitvraagt in de keuken. 'U weet toch wie Jezus heeft vermoord?', vraagt die laakstse als excuus om de huiszoeking te legitimeren. Ja, de Romeinen', antwoordt Riphagen, die het gezelschap plots vervoegt in de keuken. Deze scène aan het begin van de film illustreert op accurate wijze het karakter van Jodenjager Andries Riphagen (1909-1973). We hebben hier niet te maken met een rotsvast overtuigde dader die handelt vanuit een ideologie, maar wel met een gladde opportunist die om het even wie aan de galg praat als het hem financieel gewin kan opleveren.

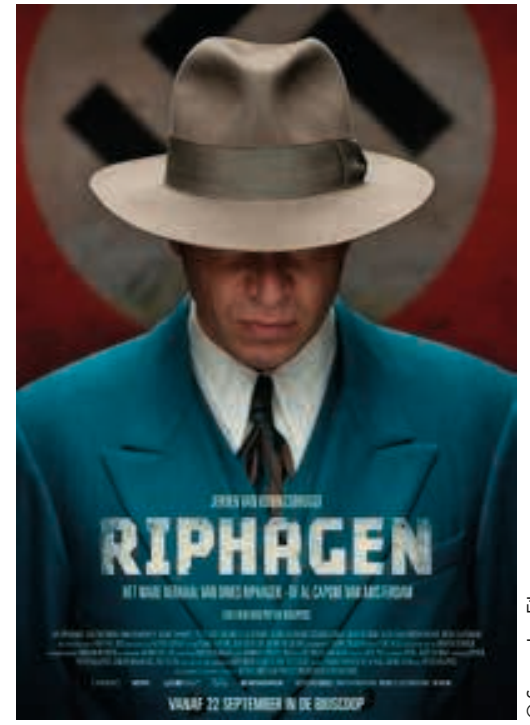

ANDRIES RIPHAGEN:

EEN CHARISMATISCH FIGUUR

D film Riphagen is gebaseerd op het gelijknatige boek van Bart Middelburg en René Ter toen al verfilmen, maar de tijdsgeest werkte tegen. Een oorlogsfilm waarin een collaborateur zonder enige gêne mensen manipuleert en er ook nog mee wegkomt, was voor producenten een brug te ver. Het meces van Zwartboek van Paul Verhoeven uit 2006 in series zols Breaking Bad dedent Het low Het levensvenaal anAndries Riphagen schreeuwt feit den ver eit dat de man zelf wel erg veel moeite deed om een
Het imago van de charismatische gangster begon hij al vroeg te ontwikkelen. Toen hij als veertienjarige voor Standard Oil in Louisiana werkte, viel hij al op door zijn dure designerkledij, inclusief de stereotiepe fedorahoed die daar bijhoorde. Eenmaal ter het hem de bijnaam 'de Al Capone van Amsterdam' op aangezien hij zich 'd de jaren dertg ook net criminele activiteiten ging inlaten. De filmposter van Riphagen is overigens een duidelijke knipoog naar de originele elkaar gemeen. Zo kon Riphagen uiterst charmant en bij had Hij moest 'betroumbar'lijken daar zelf belang schillende paestije Jor schillende partijen, Joden en nazi's. De film speelt hier De ene Capone. Beide mannen hadden inderdaad veel met handigop in meteensteeds terugkerend visueel motief. vangst, de andere keer staat hij te poseren met Joden nadat hij hen op een slinkse manier heeft overtuigd om hun juwelen en kostbaarheden aan hem af te staan. $\mathrm{Na}$ de oorlog zullen ze immers alles 'netjes' terugkrijgen. Een ander motief is een kettinkje van Sint-Chrisoffel. Riphagen krijgt het in het begin van de film toffel. Riphagen krijgt het in het begin van de film

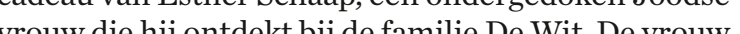
is zo ne hijontdekt bij de fanilie De Wit. De vrouw z overheid In sint-Chrin so Sint-Chistoris voor

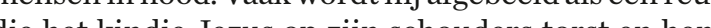
he helpt een rivier over te steken. Het is dan ook even fel won toverger gebert dit as a gebeurt dit pas nadat Esther tientallen kennissen en

amilieleden heeft overtuigd om Riphagen in vertrouwen te nemen.

OP HET VERKEERDE SPOOR

De film begint in het voorjaar van 1944. Willy Des, hoofd van de Sicherheitspolizei, houdt een toepresk Hij felicitert hen met de recente 'Jodenvangs' moedigt hen aan om ook de latste Joden in de stad op te pakk Dat oïle politiediensten in werkten an. Dat officle politiedis de Wereldoo

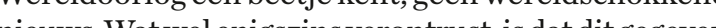
nieuws. Watwelenigszinsverontrust, is dat ditgegeven Tussen de politienane The Hij ziet eruit als een agent, maar in feite ...

- Andries Riphagen (Jeroen van Koningsbrugge)

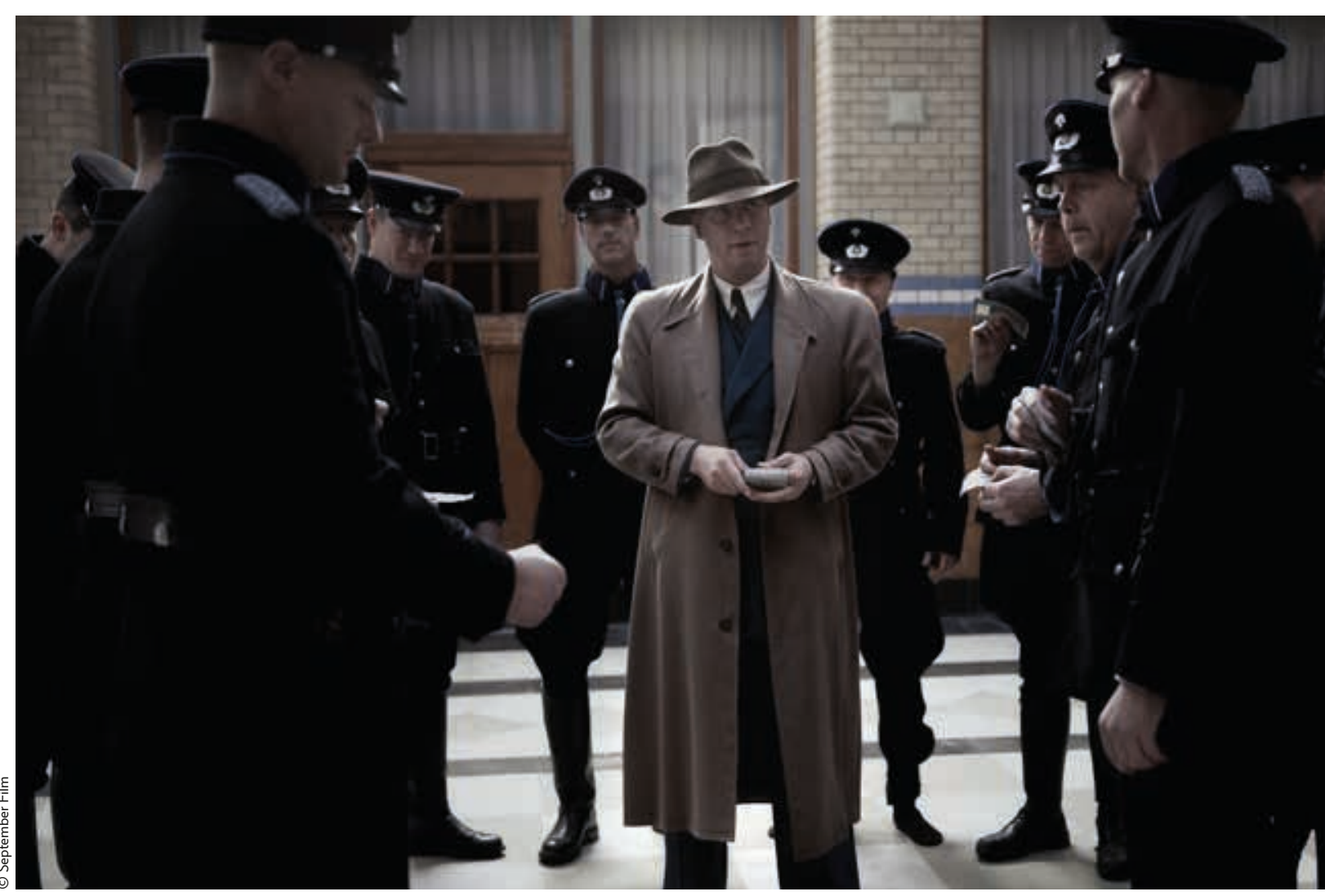


•. werkt hij voor het verzet. De film zet kijkers dus al van meet af aan op het verkeerde spoor over wie ze moeten 'vertroun dit tothetële collaber in rotentiele collaborateur zijn, zonder onderscheid in rang, stand, gender or religie. Zo maken we bijvoorceld kentis diabortrice die naast Ans van Dijk inderd.

te

Het morelecenturisande film is echter de fictieve Jan van Lienpd. Lennaal op de hoogte van de praktijwordt opejagd wild Als kijker klampen w. Je jage wa van Liempd, in de hoop dat hij de weg weet in dit aun van Lienpd, in de hoop dat hij de weg weet in dit één person reche de slakte van de film blijk alles complexer dan didijk dat van Liempd oeen betroub is ist is. Ook hijvert zichin zijn naaste

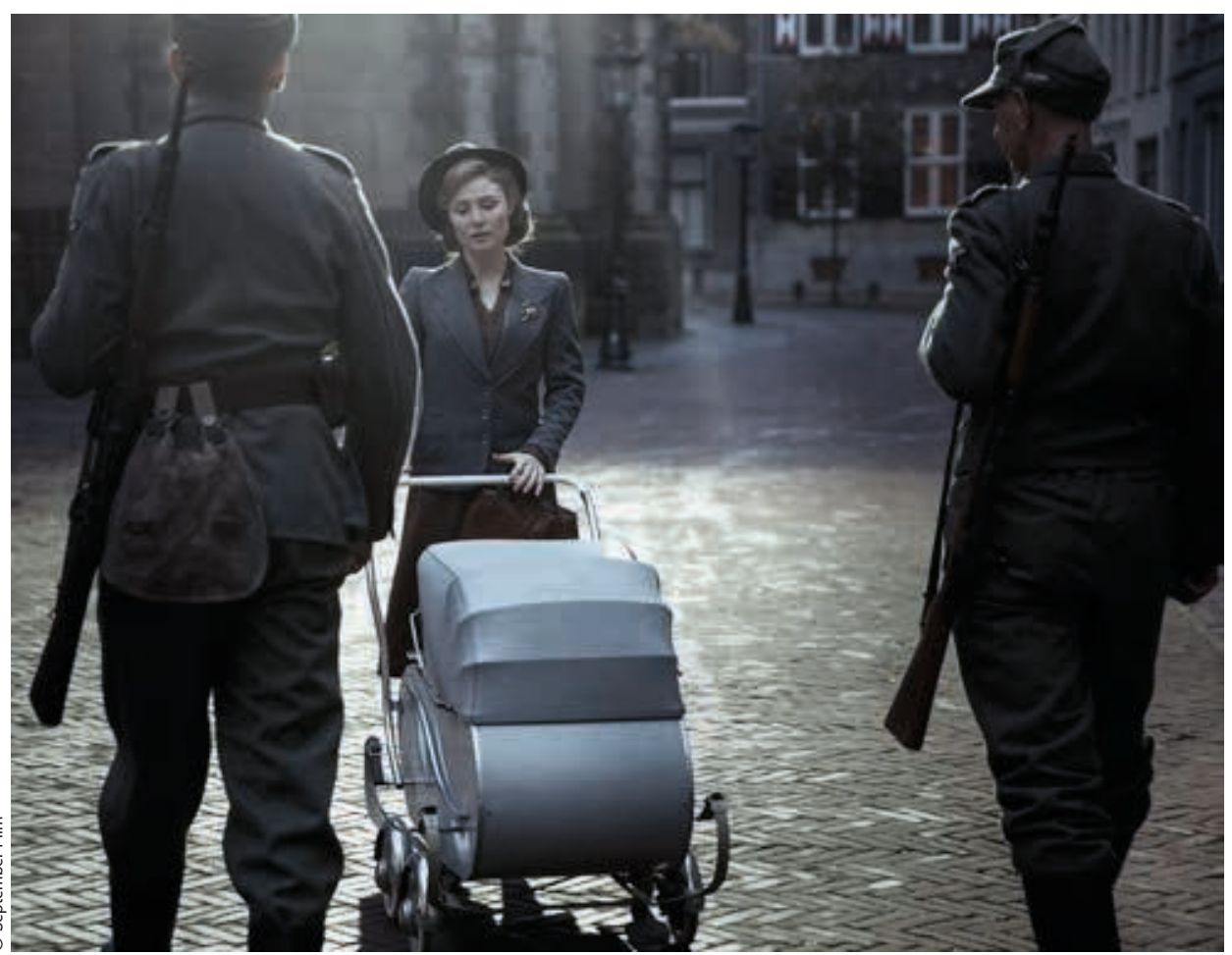

RIPHAGEN ALS TEGENGIF VOOR DE GEROMANTISEERDE NEDERLANDSE VERZETSHELD

Als we er de geschiedenis van de Nederlandse orlogsfilm op nagaan, merken we dat een overgrote meerd verzet tegen de nais te bennt voor eldis wellicht Soldat van Oranje (1977) van Paul Verhoeven. Deze prold vitun Oraje (1977) vanPaut seerde lov. Deze prent ven Erik Hazelh gernantieen jonge blonde Ne Erer die Britten men het uitzond rijke karter van de Nerlanse verzets merien uitKan moesten de Nederlons moesten de Ned bevolgeven beter te verwerken. Wewillen met deze stelling geenszins zing

Elizabeth 'Betje’ Wery (Anna
Raadsveld)

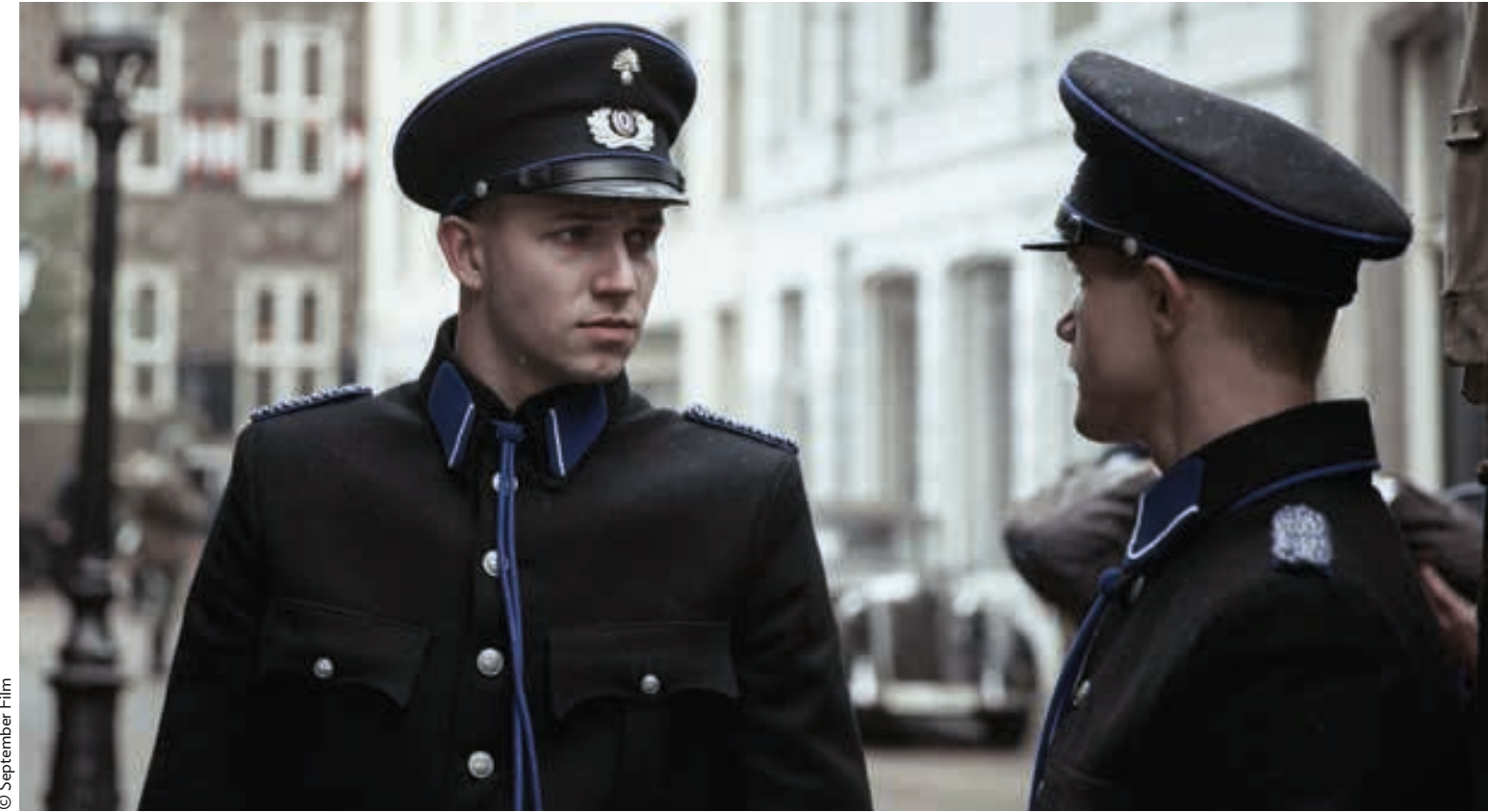

-Jan van Liempd (Kay Greidanus)

voor de Nederlandse cinema. Op nobele uitzonderingen na, zoals L'armée des ombres van Jean-Pierre Melvil uit 1969 e de docun uit 1971 word he t varzet tijda Pitiévan in der. in de cinema echter nog steeds sterk geromantiseerd. Meer dan zeventigjaar na de feitenvoelt Riphagen dan ook aan alsentegenifvor aldatheldendom. Het laat een men vo con lees bij maakt hij een bewaste keuze on zijn nedemens aan ze het publieke deb to a doze zijn belangrijk omdat zret pu boren. Het feit dat er bovendien weinig concessies wordengedaanwatbetret dew persongesengebte

Brecht Capiau Meer weten

$\diamond$ Riphagen van Pieter Kuijpers (2017)

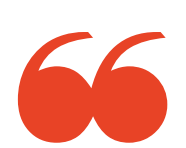

De meeste Nederlandse speelfilms over de oorlog hebben een heldhaftig karakter, denk aan Het Meisje met Het Rode Haar (1981) en Soldaat van

Oranje (1977). Maar dat er ook Nederlanders waren die tijdens de bezetting heel andere dingen uitspookten, is vrijwel niet verfilmd, behalve misschien in ziartboek (2006).

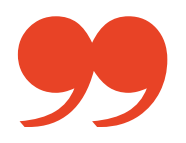

Regisseur Pieter Kuijpers over het uniete vertelperspectief van zijn film Riphagen 